\title{
Top Popular Python Libraries in Research
}

\author{
Samira Gholizadeh ${ }^{1}$ \\ ${ }^{1}$ Blast Impact and Survivability Research Unit (BISRU, University of Cape Town
}

February 25, 2022

\section{Hosted file}

Top popular Python Libraries in research.pdf available at https://authorea.com/users/441662/ articles/557751-top-popular-python-libraries-in-research 